\title{
Provide a model for establishing a comprehensive knowledge management system in knowledge-based organizations based on success factors
}

\section{Saeed Ghorbani ${ }^{*}$, Shayan Naghdi Khanachah ${ }^{2}$}

Faculty of Industrial Engineering, Malek Ashtar University of Technology, Tehran, Iran ${ }^{1,2}$ sgh14@yahoo.com ${ }^{1 *}$, shayan.en24@gmail.com ${ }^{2}$

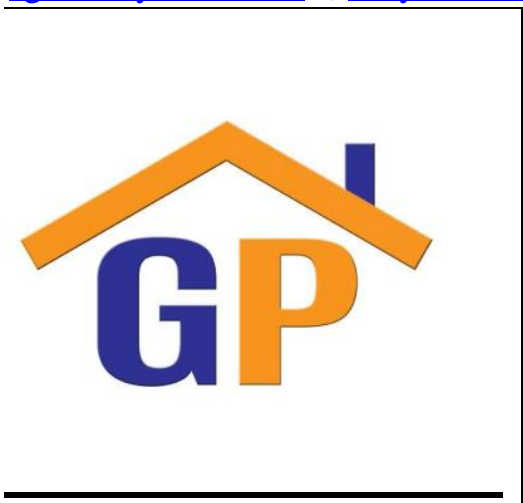

Article History

Received on 8 May 2021

$1^{\text {st }}$ Revision on 22 May 2021

$2^{\text {nd }}$ Revision on 29 May 2021

Accepted on 31 May 2021

\begin{abstract}
Purpose: This study provides a model for establishing a comprehensive knowledge management system in knowledgebased organizations based on success factors.
\end{abstract}

Research methodology: A researcher-made questionnaire was used to examine these factors and finally to present the model. The statistical population of this study is all managers and employees of knowledge-based organizations. There are 150 of them and 108 people were randomly selected as the research sample.

Result: The results of factor analysis showed that all 7 factors under study explain $65.16 \%$ of the total variance, which is acceptable. On the other hand, the results of the Friedman test also showed the first to the seventh priority of effective factors of knowledge success in construction projects, including human resource development, knowledge-based orientation, knowledge evaluation and transfer, information systems infrastructure, business culture, modeling. Finally, there was a conflict between people. A model was designed according to the mentioned priority.

Limitations: This research only described knowledge-based organizations.

Contribution: In this article, using a comprehensive knowledge management system, an attempt is made to provide a mechanism for establishing and implementing a comprehensive knowledge management system in knowledge-based organizations to help it take an important step towards capacity building to create value in processes and exchanges. The knowledge of the experts of the organization should be removed in order to direct the tacit knowledge of the experts, which is the main capital of any organization, towards this important issue.

Keywords: Key success factors, Knowledge management, Comprehensive knowledge management system, Knowledge-based organizations

How to cite: Ghorbani, S., \& Khanachah, S. N. (2020). Provide a model for establishing a comprehensive knowledge management system in knowledge-based organizations based on success factors. Annals of Management and Organization Research, 2(1), 1-12.

\section{Introduction}

In the present age, which is the age of a knowledge-based economy, knowledge plays an essential role in developing sustainable competitive advantages. Also, knowledge is a key asset for any country's success and economic growth. Ghorbani \& Khanachah (2020) have encouraged the acceptance of knowledge management with the expectation that it will lead to a sustainable competitive advantage 
and improved performance. Knowledge that is managed leads to the system's growth and initiative, and therefore, its survival is very effective (Sharma, Fantin, Prabhu, Guan, \& Dattakumar, 2016). The American Center for Quality and Productivity defines knowledge management as strategies and processes for identifying, storing, and utilizing knowledge. Proper use of knowledge and timely application of its indicators, which is knowledge management, can solve all the leading problems of an organization (Ovalle, Márquez, \& Salomón, 2004).

The purpose of KM is to find a systematic way to organize, make available the organization's intangible assets, and strengthen the culture of continuous learning and knowledge sharing in the organization (Alrawi \& Elkhatib, 2009). Most organizations are looking for knowledge management benefits to focus on knowledge management and invest heavily in information technology (M. Zahedi, Akhavan, $\&$ Naghdi Khanachah, 2020). Therefore, the need for purposeful study and extensive research on the main and key factors of success in knowledge management is vital and organizations should identify and be aware of the factors influencing the success of knowledge management actions because of neglect and inattention to these factors. The efforts of the organization in this regard will not bring any results (M. R. Zahedi \& Naghdi Khanachah, 2020).

Organizations' desire is fundamental to defining a proper knowledge management system and managing it efficiently and secretively (Arif \& Shalhoub, 2014). Therefore, the knowledge management program needs to address the key success factors for achieving optimal performance in the top-secret. Key success factors can be defined as areas in which detrimental outcomes will ensure successful competitive performance for the organization (Kluge, Stein, \& Licht, 2001). The key factors of success can be considered important areas of management planning and action in those areas can be considered useful to achieve efficiency (Sallis \& Jones, 2013). In KM, the key factors for success can be considered activities that are necessary to ensure its successful implementation. If they do not exist, these activities must be created and nurtured by Shand (1994), and if they exist, they must be developed. If knowledge management is an important determinant of an organization's success, the analysis of key factors in knowledge management is an effective tool to identify the main processes that ensure knowledge management success (Fuller, 2012; Pan \& Scarbrough, 1999; Shand, 1994).

Believing in the vital role of knowledge in achieving sustainable competitive advantage, organizations today try to systematically control the value of their knowledge assets to achieve strategic goals by using new systems and optimizing these assets. Benefit from their performance. People in projects do not usually act based on new procedures and processes defined by the organization's experts. They prefer to base their past experiences on the tasks assigned to them and use them as the basis of their tasks (Yuan, Olfman, \& Yi, 2020). One of the important tasks of knowledge management is to document their experiences and share them with other people, and in addition to maintaining the experience and knowledge of people, it also helps to promote other people (Al-Kurdi, El-Haddadeh, \& Eldabi, 2020). The main importance and application of the basic factors of knowledge management success is that the organization can achieve the desired performance (Arif \& Shalhoub, 2014). Therefore, any activity that the organization performs in implementing knowledge management must be pre-reviewed and planned for optimal performance in the success factors (Jain \& Moreno, 2015).

\section{Literature review}

\subsection{Key success factors in implementing knowledge management}

Mendoza et al (2007) consider the key factors of success to be areas in which satisfactory results are guaranteed to ensure the organization's success. Despite this, no systematic work can identify a coherent set of key success factors for implementing KM in small and medium-sized businesses (Mendoza, Marius, Pérez, \& Grimán, 2007). Studies on the implementation of KM in developed countries have also been widely focused on large organizations. Therefore, the existing factors are mainly related to large organizations and reflect the position and needs of these organizations. Implementing these factors in small and medium business environments without understanding their special conditions cannot be appropriate. Therefore, there is an urgent need to develop appropriate knowledge management approaches in small and medium-sized businesses (Ansari, Youshanlouei, \& Mood, 2012). 
Wong (2005) surveyed 31 levels of knowledge management projects in 24 companies. In this study, eight major factors were identified that have played a significant role in the successful implementation of KM. Choy and Suk (2005) have identified six important factors in the successful implementation of KM. He states that for the successful implementation of knowledge management, top management support for KM strategy, senior knowledge manager or equivalent and knowledge management infrastructure, knowledge typology and knowledge repositories, KM systems and tools, incentives Shares knowledge and supportive culture as necessary. Ayatollahi and Zeraatkar (2020) also mention the following factors: support for top management, organizational culture, technological infrastructure, knowledge management strategy, performance measurement, organizational infrastructure, activities and processes, rewards and incentives, limitations, education, human resource management, and role modeling.

Massaro et al. (2016) conducted a study entitled "Implementing Knowledge Management in Small and Medium-sized Businesses in Malaysia and Pakistan," which showed that the key factors for success were expressed in the form of 12 items, including top management support, appropriate cultural knowledge, financial resources, technological infrastructure, inter-departmental relations, human resources development, employment of knowledge-oriented people, knowledge management strategy, rewards and incentives for knowledge performance, systematic knowledge management activities and processes, core business values and organizational infrastructure (Massaro, Handley, Bagnoli, \& Dumay, 2016).

Mousavizade \& Shakibazad (2019) conducted a study entitled "Identifying and ranking the key factors of knowledge management success using the fuzzy quality performance enhancement approach: a case study" in which a qualitative-quantitative-qualitative three-stage strategy was used. In the first qualitative part and the first stage of the research, by conducting a case study, the key factors of knowledge management success and knowledge management results were identified in Meko Company. Then, in the quantitative and second stages of the research, the key factors of knowledge management success identified in the first qualitative part were identified. Using the fuzzy quality performance extension approach, it was ranked. In the second qualitative and third stages of the research, strategies for realizing and improving the key factors of knowledge management success in Meko company are presented. In this research, the key factors of knowledge management success are prioritized in the company. Meko includes "Human Resource Management", "Management Support and Leadership", "Organizational Infrastructure", "Organizational Culture", "Activities and Processes", "Motivational Measures", "Principles", "Education", "Friendly Personality" "Knowledge Management", "Information Technology" and "Measurement" (Huang \& Lai, 2012; Mousavizade \& Shakibazad, 2019).

Ghomi and Barzinpour (2018) conducted a study entitled "Identifying the success factors of knowledge management in project-based companies" in which this study tried to identify the success factors of knowledge management in these companies. In order to test the effect of cultural, organizational, structural and process factors on the effectiveness of knowledge management, the least squares method has been used. This study shows that there are cultural factors that strongly influence the success of knowledge management in addition to IT support and organizational elements. These factors in the project teams of organizations compensate for the lack of organizational procedures and lack of organizational memory (Ghomi \& Barzinpour, 2018).

Table 1. List of key success factors in implementing knowledge management from the perspective of researchers

\begin{tabular}{|c|c|}
\hline $\begin{array}{c}\text { Key success factors in } \\
\text { implementing KM }\end{array}$ & Research/year \\
\hline $\begin{array}{c}\text { Leadership and } \\
\text { leadership support }\end{array}$ & $\frac{\text { Alrawi \& Elkhatib, 2009; Ghomi \& Barzinpour, 2018; } ; \text { Huang \& Lai, }}{2012 ; \underline{\text { Karami, Alvani, Zare, \& Kheirandish, 2015; Kumar, Singh, \& }}}$ \\
\hline$\underline{\text { Haleem, 2015; Massaro et al., 2016; Wong, 2005) }}$ \\
\hline
\end{tabular}




\begin{tabular}{|c|c|}
\hline Culture & 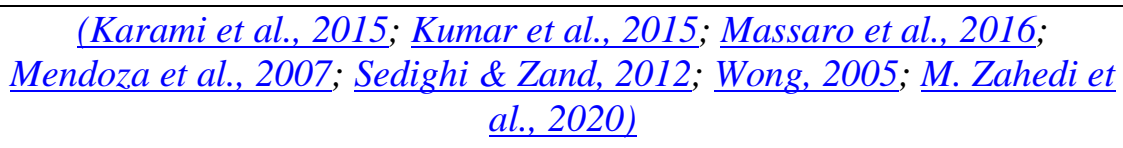 \\
\hline $\begin{array}{c}\text { Information } \\
\text { Technology }\end{array}$ & $\begin{array}{l}\text { (Huang \& Lai, 2012; Massaro et al., 2016; Pan \& Scarbrough, 1999; } \\
\text { Sedighi \& Zand, 2012; Wong, 2005; M. Zahedi et al., 2020) }\end{array}$ \\
\hline Goals and strategies & $\begin{array}{l}\text { (Huang \& Lai, 2012; Massaro et al., 2016; Mendoza et al., 2007; } \\
\text { Sedighi \& Zand, 2012) }\end{array}$ \\
\hline Evaluation system & $\frac{\text { Ghomi \& Barzinpour, 2018; } ; \text { Huang \& Lai, 2012; Kumar et al., 2015; }}{\text { Sedighi \& Zand, 2012) }}$ \\
\hline $\begin{array}{l}\text { Organizational } \\
\text { infrastructure }\end{array}$ & $\frac{(\text { Fuller, 2012; Ghorbani \& Khanachah, 2020; Mendoza et al., 2007; }}{\text { Pan \& Scarbrough, 1999; Sedighi \& Zand, 2012) }}$ \\
\hline Activities and processes & $\frac{(\text { Ghorbani \& Khanachah, 2020; Massaro et al., 2016 }}{\text { 2007; Sedighi \& Zand, 2012) }}$ Mendoza et al., \\
\hline Stimulus incentives & $\frac{\text { (Kumar et al., 2015; Mendoza et al., 2007; Sedighi \& Zand, 2012; }}{\text { Wong, 2005; M. R. Zahedi \& Khanachah, 2020) }}$ \\
\hline Resources & $\frac{\text { (Huang \& Lai, 2012; Kumar et al., 2015; } \text { Mendoza et al., 2007; Sedighi }}{\text { \& Zand, 2012) }}$ \\
\hline Education & $\frac{\text { (Ghomi \& Barzinpour, 2018; } ; \text { Huang \& Lai, 2012; Karami et al., 2015; }}{\text { Massaro et al., 2016; Sedighi \& Zand, 2012) }}$ \\
\hline $\begin{array}{l}\text { Human resources } \\
\text { management }\end{array}$ & 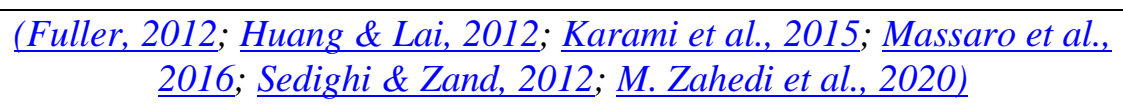 \\
\hline Modeling & $\begin{array}{c}\text { (Karami et al., 2015; Kumar et al., 2015; Mendoza et al., 2007; Pan \& } \\
\text { Scarbrough, 1999; Sedighi \& Zand, 2012; Wong, 2005) }\end{array}$ \\
\hline
\end{tabular}

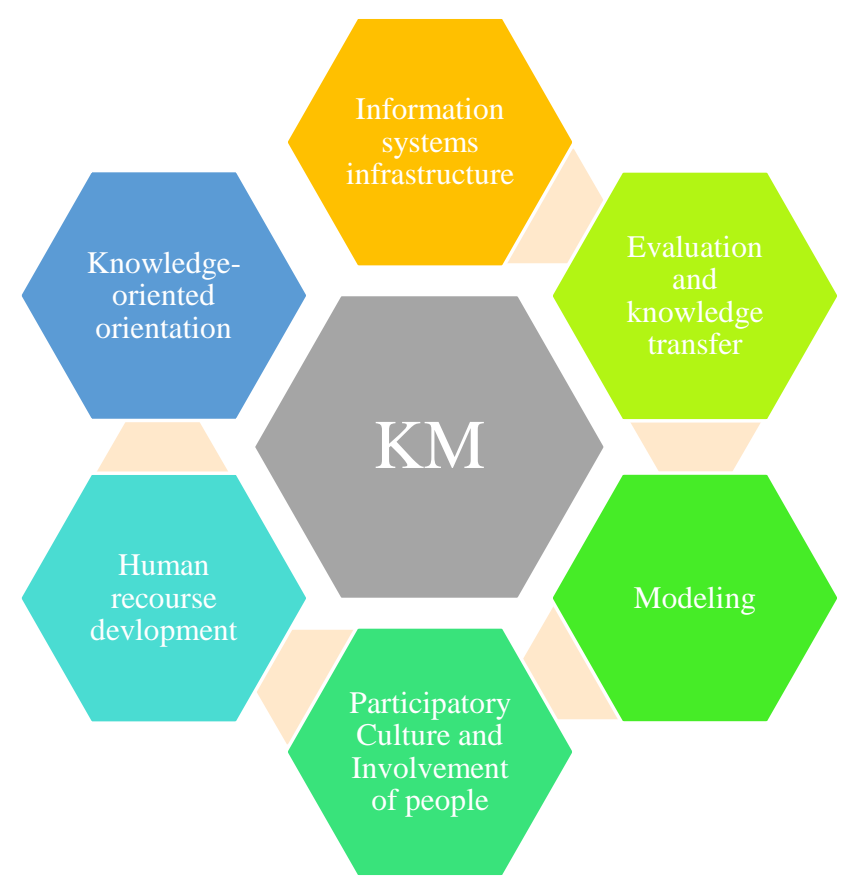

Figure 1. Conceptual model of research 


\section{Research methodology}

The statistical population of the present study will be all managers and employees of knowledge-based organizations in Tehran. There are 150 of them. To determine the minimum sample size required, the Morgan table is used for the community.

\subsection{Sample and sampling method}

The size of the study population was 150 people. Based on the Morgan table (Krejcie \& Morgan, 1970) and simple random method, 108 people were selected as the research sample.

\subsection{Research tool knowledge management questionnaire}

This press release has 67 questions and its purpose is to measure the knowledge management of knowledge-based organizations in Tehran. The scoring method is based on the Likert spectrum of 5 options, which is presented in the table of options below, as well as the points related to each option:

Table 2. Likert Scale

\begin{tabular}{|c|c|c|c|c|c|}
\hline Option & Very Little & Little & Medium & Much & Very Much \\
\hline Score & 1 & 2 & 3 & 4 & 5 \\
\hline
\end{tabular}

\subsection{Reliability of the Questionnaire}

To calculate the validity of a journal press release, various methods such as: retest, halving the test, calculating the Cronbach's alpha loss, etc. are used. In this study, a questionnaire to assess the importance of criteria among experts was completed. Cronbach's alpha coefficient was used to evaluate the reliability of the questionnaire.

$$
R_{a}=\frac{J}{J-1}\left(1-\frac{\sum s j^{2}}{S^{2}}\right)
$$

S: Total variance

$\mathrm{Sj}^{2}$ : The variance of the scores of each subset

$J^{2}$ : Number of questionnaire subset questions

\section{Findings}

The Cronbach's alpha test method was used to determine the reliability of the measuring instrument. If Cronbach's alpha is greater than 0.7, the result will be valid. For this purpose, after completing questionnaires and factor analysis and finding the factors, reliability was checked by SPSS software using Cronbach's alpha test.

Table 3. Cronbach's alpha values of knowledge management questionnaire components

\begin{tabular}{|c|c|c|}
\hline Component & Number of questions & Cronbach's values \\
\hline human recourse devlopment & 15 & 0.71 \\
\hline Knowledge-oriented orientation & 11 & 0.72 \\
\hline Participatory culture and people's involvement & 17 & 0.70 \\
\hline information systems & 7 & 0.85 \\
\hline Evaluation and knowledge transfer & 12 & 0.73 \\
\hline Modeling & 5 & 0.78 \\
\hline The whole questionnaire & 68 & 0.77 \\
\hline
\end{tabular}


Given that Cronbach's alpha values for all components and total questions of the questionnaire are higher than 0.7. Therefore, the questionnaire has acceptable reliability.

The exploratory factor analysis method was used to determine the factors of knowledge management. Exploratory factor analysis is a method by which different factors can be discovered from the questionnaire.

\subsection{Inferential analysis of data}

In the hypothesis test or significance test, the researcher rejects or accepts the null hypothesis. If $\mathrm{H} 0$ is accepted, it is assumed that $\mathrm{H} 1$ is rejected and if $\mathrm{H} 0$ is rejected, $\mathrm{H} 1$ is accepted. To determine the statistical significance of a research study, the researcher must determine its probable level or significance level; To test the null hypothesis against it if the results of a possible study show less than this level.

\subsection{Hypotheses tests}

The KMO statistic was about 0.92 , which indicates the adequacy of sampling. Significance of the Bartlett's Test also showed that the conditions for factor analysis were met.

Table 4. Result of Bartlett's Test of Sphericity

\begin{tabular}{|c|c|}
\hline KMO Scale & $0 / 92$ \\
\hline Bartlett's Test of Sphericity & $18520 / 27$ \\
\hline Degrees of freedom & 2210 \\
\hline Significance level & $0 / 00$ \\
\hline
\end{tabular}

The second column of Table 5 shows the amount of variance of each variable, which the set of factors could explain. The values of this variance fluctuate between 0 and 1 . The closer the values are to 1 , the better. Also, based on what can be seen, it can be said that the sum of the extracted factors and how much they were able to explain the changes in each item.

Table 5. Common factors and indicators

\begin{tabular}{|c|c|c|c|}
\hline & Indicators & primitive & Extraction \\
\hline & Attracting people based on knowledge competencies & 1 & $0 / 71$ \\
\hline ฐ & Knowledge competency-based promotion & 1 & $0 / 70$ \\
\hline$\frac{\tilde{2}}{2}$ & People's participation in education & 1 & $0 / 77$ \\
\hline 0 & Emphasis on the role of scholars & 1 & $0 / 74$ \\
\hline$\tilde{5}$ & Knowledge-based payment & 1 & $0 / 81$ \\
\hline$\Xi$ & Provide training in problem solving and creativity & 1 & $0 / 73$ \\
\hline$\overline{3}$ & Human Resource Development Program & 1 & $0 / 70$ \\
\hline$\stackrel{s}{2}$ & Mechanisms for disseminating research & 1 & $0 / 79$ \\
\hline$\stackrel{2}{2}$ & Valuing people's knowledge creation in projects & 1 & $0 / 84$ \\
\hline & Resource allocation with knowledge promotion approach & 1 & $0 / 77$ \\
\hline
\end{tabular}




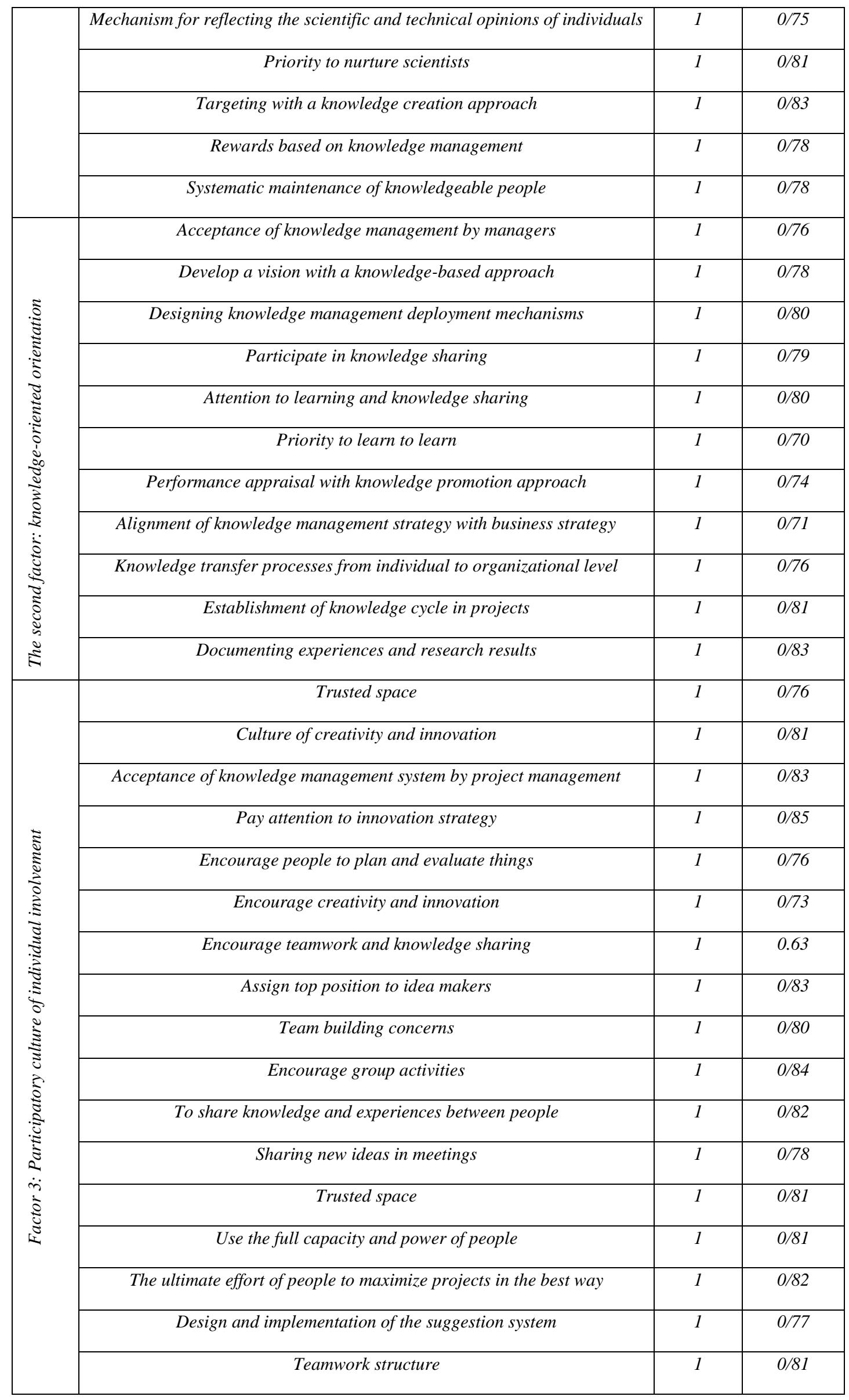




\begin{tabular}{|c|c|c|c|}
\hline \multirow{7}{*}{ 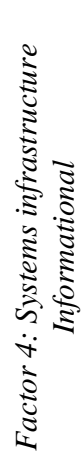 } & Existence of complete IT infrastructure & 1 & $0 / 80$ \\
\hline & Internal support for knowledge sharing & 1 & $0 / 87$ \\
\hline & IT capability & 1 & $0 / 79$ \\
\hline & Virtual group discussion mechanisms & 1 & $0 / 79$ \\
\hline & Proportion of information system with knowledge sharing & 1 & $0 / 82$ \\
\hline & Existence of user-friendly electronic systems & 1 & $0 / 82$ \\
\hline & Use expert systems and decision support & 1 & $0 / 83$ \\
\hline \multirow{12}{*}{ 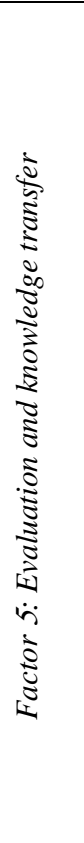 } & Teaching methods to transfer knowledge to individuals & 1 & $0 / 76$ \\
\hline & Designing appropriate knowledge assessment mechanisms & 1 & $0 / 78$ \\
\hline & Educational methods based on systems thinking & 1 & $0 / 84$ \\
\hline & Calculate appropriate scales for knowledge assessment & 1 & $0 / 78$ \\
\hline & Teaching methods based on group learning development & 1 & $0 / 79$ \\
\hline & Emphasis on network structure to promote knowledge & 1 & $0 / 79$ \\
\hline & Processes to facilitate knowledge exchanges & 1 & $0 / 73$ \\
\hline & Facilitate access to knowledge & 1 & $0 / 85$ \\
\hline & Communication networks for information distribution & 1 & $0 / 84$ \\
\hline & Knowledge transfer using the teacher-student system & 1 & $0 / 77$ \\
\hline & Attention to knowledge capital in performance appraisal & 1 & $0 / 82$ \\
\hline & Structure facilitating knowledge exploration & 1 & $0 / 73$ \\
\hline \multirow{5}{*}{ 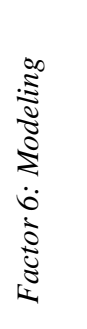 } & Existence of processes for modeling & 1 & $0 / 70$ \\
\hline & Comparison of work processes of research projects with other projects & 1 & $0 / 79$ \\
\hline & Existence of guidelines for modeling & 1 & $0 / 77$ \\
\hline & Existence of knowledge promotion standards & 1 & $0 / 82$ \\
\hline & Encourage people to emulate the best experiences of others & 1 & $0 / 83$ \\
\hline
\end{tabular}

Using principal component analysis and varimax rotation, all 67 research variables were summarized into 7 factors. These factors explain $65.16 \%$ of the total variance, which indicates the desirability of the computed model in explaining the factors affecting the success of the knowledge management system. The first factor and development of human resources with a variance of 20.84 is in priority and the factor of knowledge-oriented orientation with a variance of 14.58 in the second place, participatory factor and culture and participation of individuals with a variance of 10.94 in the third place, the fourth factor of the Minister of Information Systems Explains the variance of the dependent variable at about 9.86. The fifth factor is evaluation and knowledge transfer with a variance of 4.59. The modeling factor with a variance of 2.27 is in sixth place. 


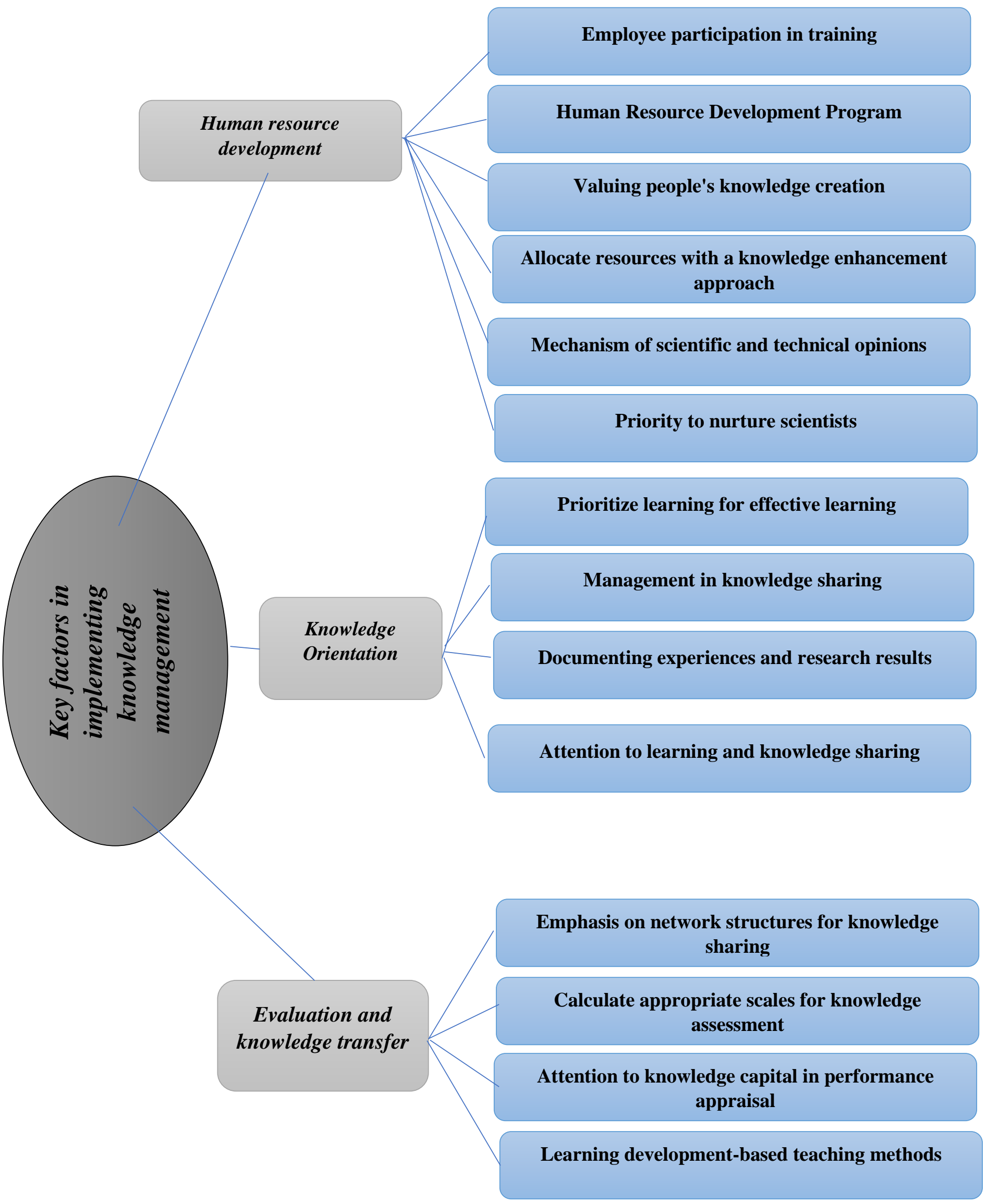

Figure 2. Model of key factors in implementing knowledge management 


\section{Conclusion}

Results obtained from the relationship matrix, there is a relationship between all dimensions and items. Also, some relationships are strong and some are weak. Finally, the conceptual model is accepted in the literature section. In the next part, the prioritization of dimensions is determined so that the first to third priorities of the dimensions are related to human resource development, knowledge-based orientation, and evaluation and knowledge transfer. If in the initial model only all dimensions are mentioned without any prioritization. Also, all components related to dimensions were accepted. Finally, the model (Figure 2) is accepted.

Also, to establish a knowledge management system in the organization, we need a model and framework for deployment, which is presented in 7 steps and the actions that are required in each step are as follows:

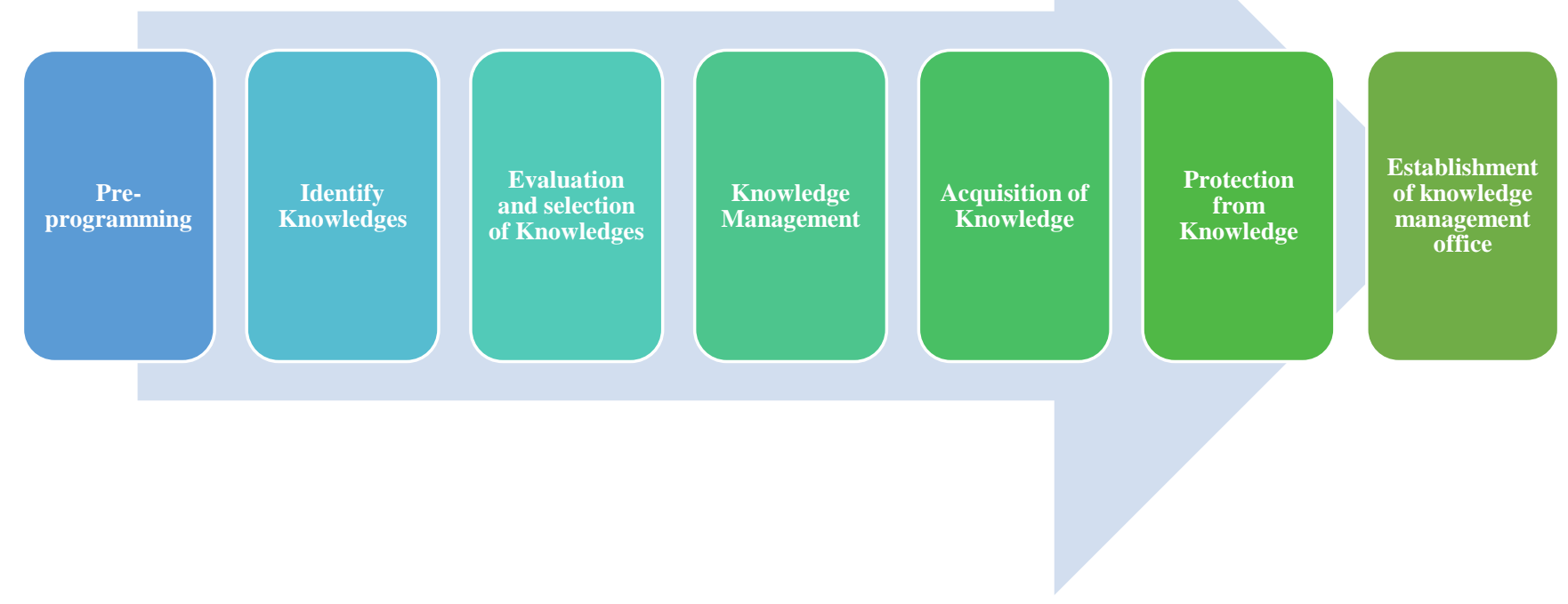

Figure 3. Step-by-step model of requirements for establishing a knowledge management system in the organization

- Pre-programming

- Holding coordination meetings with experts

- Holding symposium workshops

- Understanding the current situation of organizations and companies

- Assess the current state of knowledge management in the organization

- Identify Knowledges

- Formation of specialized working groups

- Drawing a knowledge tree

- Future research and determination of future required knowledge

- Evaluation and selection of Knowledge

- Develop criteria for measuring and evaluating knowledge

- Develop a method for applied knowledge assessment

- Obtaining the opinions of specialized working groups

- Category of knowledge

- Knowledge Management

Select the appropriate sample with the opinion of the organization's knowledge experts Identify knowledge 


\section{- Acquisition of Knowledge}

- Select a sample to perform the processes

- Identify knowledge holders

- Determining the level of mastery of knowledge holders

- Determining the appropriate method of knowledge transfer

- Protection from Knowledge

- How to maintain and update the knowledge management system

- Knowledge protection programs

- Knowledge application program

- Establishment of Knowledge Management Office

- Develop a structure and job description for employees

- Appoint training experts

\section{References}

Al-Kurdi, O. F., El-Haddadeh, R., \& Eldabi, T. (2020). The role of organisational climate in managing knowledge sharing among academics in higher education. International Journal of Information Management, 50, 217-227.

Alrawi, K., \& Elkhatib, S. (2009). Knowledge management practices in the banking industry: Present and future state-case study. Journal of Knowledge Management Practice, 10(4), 68-84.

Ansari, M., Youshanlouei, H. R., \& Mood, M. M. (2012). A Conceptual model for success in implementing knowledge management: A case study in Tehran municipality.

Arif, M. J., \& Shalhoub, M. H. B. (2014). Critical success factors with its effective role in knowledge management initiatives in public and private organizations in saudi Arabia: experts perspectives. Life Science Journal, 11(6), 636-645.

Ayatollahi, H., \& Zeraatkar, K. (2020). Factors influencing the success of knowledge management process in health care organisations: a literature review. Health Information \& Libraries Journal, 37(2), 98-117.

Choy, C. S., \& Suk, C. Y. (2005). Critical factors in the successful implementation of knowledge management. Journal of Knowledge Management Practice, 6(1), 234-258.

Fuller, S. (2012). Knowledge management foundations: Routledge.

Ghomi, H., \& Barzinpour, F. (2018). Identifying the success factors of knowledge management tools in research projects (Case study: A corporate university). Management Science Letters, 8(8), 805-818.

Ghorbani, S., \& Khanachah, S. N. (2020). Providing a framework for knowledge sharing in knowledgebased organizations according to social capital indicators. Annals of Management and Organization Research, 1(4), 271-284.

Huang, L.-S., \& Lai, C.-P. (2012). An investigation on critical success factors for knowledge management using structural equation modeling. Procedia-Social and Behavioral Sciences, 40, 24-30.

Jain, A. K., \& Moreno, A. (2015). Organizational learning, knowledge management practices and firm's performance. The Learning Organization.

Karami, M., Alvani, S. M., Zare, H., \& Kheirandish, M. (2015). Determination of critical success factors for knowledge management implementation, using qualitative and quantitative tools (case study: Bahman automobile industry). Iranian Journal of Management Studies, 8(2), 181-201.

Kluge, J., Stein, W., \& Licht, T. (2001). Knowledge unplugged: The McKinsey global survey of knowledge management: Springer.

Kumar, S., Singh, V., \& Haleem, A. (2015). Critical success factors of knowledge management: modelling and comparison using various techniques. International Journal of Industrial and Systems Engineering, 21(2), 180-206.

Krejcie, R. V., \& Morgan, D. W. (1970). Determining sample size for research activities. Educational and psychological measurement, 30(3), 607-610.

Massaro, M., Handley, K., Bagnoli, C., \& Dumay, J. (2016). Knowledge management in small and medium enterprises: a structured literature review. Journal of knowledge management. 
Mendoza, L. E., Marius, A., Pérez, M., \& Grimán, A. C. (2007). Critical success factors for a customer relationship management strategy. Information and software technology, 49(8), 913-945.

Mousavizade, F., \& Shakibazad, M. (2019). Identifying and ranking CSFs for KM implementation in urban water and sewage companies using ISM-DEMATEL technique. Journal of knowledge management.

Ovalle, M. d. R. G., Márquez, J. A. A., \& Salomón, S. D. M. (2004). A compilation of resources on knowledge cities and knowledge-based development. Journal of knowledge management.

Pan, S. L., \& Scarbrough, H. (1999). Knowledge management in practice: An exploratory case study. Technology analysis \& Strategic management, 11(3), 359-374.

Sallis, E., \& Jones, G. (2013). Knowledge management in education: Enhancing learning \& education: Routledge.

Sedighi, M., \& Zand, F. (2012). Knowledge management: Review of the Critical Success Factors and development of a conceptual classification model. Paper presented at the 2012 Tenth International Conference on ICT and Knowledge Engineering.

Shand, R. M. (1994). User manuals as project management tools. i. theoretical background. IEEE Transactions on Professional Communication, 37(2), 75-80.

Sharma, R., Fantin, A.-R., Prabhu, N., Guan, C., \& Dattakumar, A. (2016). Digital literacy and knowledge societies: A grounded theory investigation of sustainable development. Telecommunications Policy, 40(7), 628-643.

Wong, K. Y. (2005). Critical success factors for implementing knowledge management in small and medium enterprises. Industrial management \& Data systems.

Yuan, X., Olfman, L., \& Yi, J. (2020). How do institution-based trust and interpersonal trust affect interdepartmental knowledge sharing? In Information Diffusion Management and Knowledge Sharing: Breakthroughs in Research and Practice (pp. 424-451): IGI Global.

Zahedi, M., Akhavan, P., \& Naghdi Khanachah, S. (2020). Identifying the Key Barriers to Knowledge Management and Lessons Learned in the Project-Based Military Organizations. MILITARY MANAGEMENT QUARTERLY, 19(76), 29-68.

Zahedi, M. R., \& Khanachah, S. N. (2020). The effect of knowledge management processes on organizational innovation through intellectual capital development in Iranian industrial organizations. Journal of Science and Technology Policy Management.

Zahedi, M. R., \& Naghdi Khanachah, S. (2020). Designing and implementing a model of organizational readiness assessment to become a knowledge-based organization: Case study an Iranian research center. 